\title{
Experimental Evidence for Differences in the Prosocial Effects of Binge-Watched versus Appointment-Viewed Television Programs*
}

\author{
Thomas J Billard \\ Annenberg School for Communication \& Journalism, \\ University of Southern California \\ tbillard@usc.edu
}

March 11, 2018

\begin{abstract}
This study investigated the influence of television consumption patterns on changes in attitudes toward depicted social out-groups. Participants were randomly assigned to view six episodes of Amazon's Transparent, a comedy-drama program about a family whose father comes out as a transgender woman, in either one three-hour ("binge-watching") session or six weekly halfhour ("appointment-viewing") sessions. Across both groups, we found exposure to the narrative reduced anti-transgender prejudice. Counter to the predictions of the Extended-Elaboration Likelihood Model and the Entertainment Overcoming Resistance Model, however, improvement of prejudice toward transgender people was not predicted by narrative or character involvement. Rather, reduction in prejudice was an outcome of viewing condition such that those who viewed the program on a schedule of one episode per week exhibited lower levels of post-exposure prejudice than those who binge-watched, and their attitudinal changes were more persistent three weeks later. Results are discussed in the context of the original Elaboration Likelihood Model, proposing mechanisms for further testing.
\end{abstract}

Keywords binge-watching, television, online streaming, transgender, media effects, experiment

Cite as Billard, Thomas J. "Experimental Evidence for Differences in the Prosocial Effects of Binge-Watched versus Appointment-Viewed Television Programs." Journalism 83 Mass Communication Quarterly, forthcoming.

\footnotetext{
*The author would like to thank Larry Gross, Peter Monge, Dmitri Williams, Ruthie Kelly, Rachel Moran, and Anna Loup for their helpful comments on earlier drafts of this article. The author would also like to thank the anonymous reviewers for their constructive insights that strengthened this article immensely. This research was supported by an Annenberg Doctoral Student Summer Research Fellowship from the University of Southern California's Annenberg School for Communication and Journalism.
} 


\section{Introduction}

One of the more popular prosocial effects in mass media research has been the improvement of intergroup relations. A wide body of literature in communication has found mediated intergroup contact, especially through fictional narratives, can decrease prejudice against social out-groups and increase acceptance, both socially and in policy (e.g., Bond \& Compton, 2015; Ortiz \& Harwood, 2007; Schiappa et al., 2005, 2006). However, in the contemporary entertainment media environment, representations of social out-groups are highly fragmented along the fault lines of "new" and "old" media. Indeed, past research has found representations of a variety of social out-groups are far more frequent in entertainment media produced and/or distributed by online streaming services than that produced/distributed by the "traditional" cable, network television, and film providers (Cook, 2018; Corfield, 2017; Smith et al., 2016). For example, Smith and colleagues (2016) found all substantive transgender representations were in media produced by or for online streaming services.

This stark difference in the distribution of diverse representations between streaming services and "traditional" network and cable television becomes particularly significant when one considers the phenomenon of binge-watching, or the consumption of television programs in "binges" of several consecutive hours rather than on the traditional network and cable schedule of one episode per week (Schweidel \& Moe, 2016). Binge-watching is not a new phenomenon; it emerged with the popularization of DVD box sets prior to the development of online streaming services (Jenner, 2016). Nonetheless, binge viewing behavior has reached critical mass with the proliferation of online television distribution. As of 2017, $71 \%$ of American adults have had a subscription streaming service like Netflix, Hulu, or Amazon Prime, and an estimated $60 \%$ of subscribers binge-watch programs at least once per week (Morning Consult, 2018a, 2018b). Among subscribers aged 18 to 29 that number rises to $73 \%$, with $60 \%$ binge-watching several times per week (Morning Consult, 2018a). As television producers consider how to court key audiences, this prevalence of bingewatching becomes a key factor in how shows are made in every domain of production, from writing to distribution (Bernardin, 2018; Jenner, 2016). Given, then, that online streaming services differ from network and cable television both in their frequency of social out-group representation and in their dominant viewing patters, how might the prosocial effects of these representations differ? If mode of consumption differs - particularly pertaining to the timeline of viewing - might the observed effects also differ? Little research has investigated this matter.

Moving to fill this gap in the literature, the present study employed an experimental design to examine whether fictional television narratives depicting social out-groups produce different effects when they are consumed along the "binge-watching" model of television viewing rather than the traditional model of one-episode-per-week. Investigating the influence of Amazon's Transparent on viewers' prejudice toward transgender people, we found exposure to the narrative indeed reduced anti-transgender prejudice. Counter to predictions of the Extended-Elaboration Likelihood Model (Slater \& Rouner, 2002) and the entertainment overcoming resistance model (Moyer-Gus, 2008), however, improvement of prejudice toward transgender people was not predicted by narrative or character involvement. Rather, reduction in prejudice was an outcome of viewing condition such that those who viewed the program on a schedule of one episode per week exhibited lower levels of post-exposure prejudice than those who binge-watched. Moreover, their attitudinal changes were more persistent three weeks later.

\subsection{The Prosocial Effects of Mediated Intergroup Contact}

One of the social powers of media is the capacity to facilitate "contact" between groups of people who would otherwise never meet. This mediated intergroup contact offers opportunities for nonhostile interactions between social in-group and out-group members that ultimately lead to more 
positive intergroup attitudes (Joyce \& Harwood, 2014; Ortiz \& Harwood, 2007). In perhaps the clearest articulation of this principle, Schiappa and colleagues (2005) posited these mediated interactions constitute "parasocial contact," a synthesis of Allport's (1954) contact hypothesis and Horton and Wohl's (1956) conception of "parasocial interaction." This combined framework, they argued, suggests that, through offering pseudo-interpersonal interaction with avoided or otherwise un-encountered social out-groups, fictional narratives can decrease levels of prejudice against outgroup members in non-mediated contexts (Schiappa et al., 2005, 2006).

Indeed, a wealth of literature has demonstrated parasocial or mediated intergroup contact with social minorities and stigmatized groups through fictional narratives decreases social distance from and reduces prejudice against members of those groups (e.g., Chung \& Slater, 2013; Hoffner \& Cohen, 2012; Mangelschots, 2017; Ortiz \& Harwood, 2007; Riggle et al., 1996; Schiappa et al., 2005, 2006), and influences policy opinions pertaining to them (e.g., Bond \& Compton, 2015). Much of this research has investigated how mediated contact with gay characters influences heterosexual viewers' attitudes toward gay men (Bond \& Compton, 2015; Ortiz \& Harwood, 2007; Schiappa et al., 2005, 2006; Riggle et al., 1996). Particularly for those with little interpersonal contact with gay people, this body of research has consistently found mediated exposure decreases anti-gay prejudice (Schiappa et al., 2005, 2006; Bond \& Compton, 2015). Other research has extended these findings to other out-groups. Research by Mangelschots (2017), for example, found parasocial contact with the character Kaat Bomans, a transgender woman on the Belgian soap opera Thuis, reduced prejudice against transgender individuals. Therefore, we hypothesize

H1: exposure to a social out-group character will result in lower levels of prejudice against that social group at Time 2 (post-exposure) than Time 1 (pre-exposure).

However, significant research has demonstrated mediated intergroup contact alone is not an absolute driver of positive attitudinal change. Rather, the capacity for contact to positively influence attitudes comes, at least in part, from the development of relationships with out-group characters. For example, Hoffner and Cohen (2012) found the development of parasocial relationships with the character Monk, a detective with obsessive-compulsive disorder (OCD), decreased belief in OCDrelated stereotypes (see also Tian \& Hoffner, 2010). Whereas parasocial contact refers to the mere exposure of viewers to out-group media figures (Schiappa et al., 2005, 2006), parasocial relationships refer to viewers' development of cognitive and affective involvements with those figures (Auter \& Palmgreen, 2000; Giles, 2002; Rubin \& McHugh, 1987; Rubin et al., 1985; Rubin \& Rubin, 2001). As Dibble, Hartman, and Rosaen (2016) compellingly argued in their conceptual clarification, whereas parasocial contact consists of a simulated mutual experience during the viewing experience, "parasocial relationship refers to a longer-term association that may begin to develop during viewing, but also extends beyond the media exposure situation" (p. 25). That is, if we analogize these two types of mediated interactions to interpersonal interactions, parasocial contact constitutes conversation, while parasocial relationships constitute relational investments such as friendship (Eyal \& Dailey, 2012; Rubin \& McHugh, 1987; Tukachinsky, 2010). Indeed, Eyal and Daily (2012) demonstrated the same processes of relational investment that underlie interpersonal friendships predicted the development of viewers' parasocial relationships with fictional characters.

Yet, despite their differences, parasocial contact and parasocial relationships are closely related. As Schiappa and colleagues (2005) noted, parasocial contact facilitates the development of further parasocial relationships, which in turn drive attitudinal changes. In their words,

for our purposes, we treat PSI [parasocial interaction] as contact or exposure and use the phrase parasocial response as shorthand for the cognitive and affective reactions we have to such contact. ? And, just as interpersonal interaction can lead to various sorts 
of interpersonal responses and relationships, parasocial interaction can lead to various sorts of parasocial responses and (one-sided) relationships. (Schiappa et al., 2005, p. 96)

These relationships can result from positive parasocial responses that yield positive outcomes, but so too can relationships form from negative parasocial responses that yield negative outcomes (Dibble \& Rosaen, 2011).

Rubin and McHugh (1987) offered empirical evidence of such a process, finding parasocial relationships were arrived at by first moving from social and task attraction to parasocial interaction, and then finally to relationship importance. Moreover, Schiappa and colleagues (2006) found viewing frequency, in combination with parasocial interaction, predicted positive attitude change, while Cohen (1997) found having strong parasocial relationships with characters increased viewers' likelihood of continuing to watch the program. As such, the development of parasocial relationships is a cyclical process whereby contact and relationship strength bolster one another, ultimately leading to greater attitude change. Therefore, we hypothesize

H2: participants who develop stronger parasocial relationships with a social out-group character will exhibit lower levels of prejudice against that social group post-exposure compared to those who develop weaker parasocial relationships.

\subsection{The Effects of Narrative and Character Involvement in Fictional Me- dia}

A wide body of literature has concerned itself with how fictional media influence individuals' attitudes and behaviors (e.g., Green \& Brock, 2000; Moyer-Gus, 2008; Moyer-Gus \& Nabi, 2010; Murphy et al., 2011; Slater \& Rouner, 2002), and various causal mechanisms have been identified over time. While parasocial relationships were among the first mechanisms to be identified (Horton \& Wohl, 1956), many others have since developed robust lines of inquiry. Scholars have subsequently attempted to unify understandings of these mechanisms in new theoretical frameworks. Building on Petty and Cacioppo's (1986) elaboration likelihood model (ELM), which suggests audiences are most durably persuaded when they have sufficient motivation (e.g., personal relevance) and ability (cognitive, emotional, etc.) to process a persuasive message, Slater and Rouner (2002) proposed engagement with narratives overcomes the potential lack of either. This extended elaboration likelihood model (E-ELM), they argued, indicates "absorption or engagement with the narrative" (Slater \& Rouner, 2002, p. 178) overcomes the lack of personal issue relevance and increases the ability to understand, thereby increasing the likelihood of enduring story-consistent attitudes.

Synthesizing E-ELM with insights from social cognitive theory (Bandura, 2009), Moyer-Gus (2008) proposed a more thorough entertainment overcoming resistance model (EORM). Positioned in the context of reactance, counter-arguing, and selective avoidance, among other forms of persuasion resistance, EORM maintains the narrative format of fictional entertainment media helps overcome these forms of resistance via the "emotional experience of being swept up into the narrative itself and becoming involved with the characters therein" (Moyer-Gus, 2008, p. 408). Indeed, MoyerGus and Nabi (2010) found, as predicted by EORM and E-ELM, exposure to a dramatic narrative reduced persuasion resistance, and the reduction in resistance was associated with what MoyerGus (2008) referred to as narrative involvement and character involvement. In addition to the development of parasocial relationships already discussed, the elements of character involvement include identification with the media character, perceived similarity to the character, and liking the character, while narrative involvement includes transportation into the narrative and enjoyment of the narrative (Moyer-Gus, 2008). 


\subsubsection{Character involvement}

In his seminal work on identification, Cohen (2001) wrote, "identification is a mechanism through which audience members experience reception and interpretation of the text from the inside, as if the events were happening to them" (p. 245). He further argued, through identifying with media figures, audience members "experience social reality from other perspectives" and thus develop alternative social attitudes (Cohen, 2001, p. 246). Numerous studies have since demonstrated the significant impact of identification on attitudinal and behavioral change, including increases in social acceptance (e.g., de Graaf et al., 2012; Eyal \& Dailey, 2012; Joyce \& Harwood, 2014; Tal-Or \& Cohen, 2010).

Despite being related to identification in several ways, perceived similarity is different in that it involves a direct comparison of oneself and the media character, rather than empathy and perspectivetaking (Eyal \& Rubin, 2003; Moyer-Gus, 2008). Building on similar findings of past work, Tian and Hoffner (2010) found perceived similarity between oneself and a media character strongly impacts the development of parasocial relationships (see also Cohen, 2006; Eyal \& Rubin, 2003; Hoffner \& Cantor, 1991; Klimmt et al., 2006). Likewise, Hoffner and Buchanan (2005) found perceived similarity increased viewers' identification with the similar character.

Again related to, yet distinct from, identification, liking a media character has been found to have a significant positive effect on both the strength of parasocial relationship (Dibble \& Rosaen, 2011) and the magnitude of attitudinal change toward social out-groups (Joyce \& Harwood, 2014). Indeed, Schiappa and colleagues (2005) found both perceived similarity and liking of out-group characters were associated with reduction in prejudice against the depicted out-groups.

\subsubsection{Narrative involvement}

Whereas identification, similarity, and liking relate to viewers' cognitive and emotional responses to characters, transportation refers to the general feeling of immersion in the fictional narrative (Green \& Brock, 2000; Green et al., 2004; Moyer-Gus, 2008; Tal-Or \& Cohen, 2010). Both Chung and Slater (2013) and Murphy and colleagues (2011) have found transportation greatly influences viewer attitudes. Moreover, Chung and Slater (2013) found transportation was not negatively impacted by a character's stigmatized identity, meaning viewers who experience high levels of transportation may still engage with the character and thus be attitudinally influenced.

Chung and Slater (2013) additionally found viewers' narrative enjoyment was not negatively impacted by a character's stigmatized identity. Although Hartmann and his colleagues (Hartmann \& Klimmt, 2005; Hartmann \& Goldhoorn, 2011; Klimmt et al., 2006) have argued enjoyment is an outcome of parasocial interaction, rather than a predictor, Moyer-Gus's (2008) EORM suggests that, through reducing selective avoidance and message resistance, enjoyment should increase acceptance of message-consistent attitudes.

Taking these findings together, we hypothesize

H3: participants who experience greater narrative and character involvement - that is, identification, perceived similarity, liking, transportation, and/or enjoyment-will exhibit lower levels of prejudice against the depicted social out-group post-exposure compared to those who experience lesser narrative and character involvement.

\subsection{The Effects of Binge-Watched Television}

While television media have traditionally been consumed via networks or cable, they are increasingly consumed via online streaming services (Jenner, 2016). As of 2017, $71 \%$ of American adults have had a subscription streaming service like Netflix, Hulu, or Amazon Prime (Morning Consult, 2018b). Attendant to this shift to streaming services has been a shift to "binge-watching" as a dominant 
mode of consumption (Jenner, 2016). According to a survey conducted by Morning Consult (2018a), $60 \%$ of respondents reported binge-watching television at least once per week, and Schweidel and Moe's (2016) study of Hulu data found in over $50 \%$ of television viewing sessions viewers watched two or more episodes. Furthermore, research by Ameri and colleagues (2017) indicates binge-watching incidences, at least among anime viewers, are steadily increasing over time. Although definitions of "binge-watching" range from "the consumption of multiple episodes of a television series in a short period of time" (Schweidel \& Moe, 2016, p. 1; see also Pena, 2015; Walton-Pattison et al., 2016) to two to three continuous hours of programming (Devasagayam, 2014; Pittman \& Sheehan, 2015), we adopted for the present study Ameri \& colleague's (2017) statistically-robust definition of viewing three or more hours in a single day.

As binge-watching has become more prominent, a small but burgeoning literature on the phenomenon has developed. Much of this early literature investigated outcomes of binge-watching behavior. For instance, Pena (2015) found, depending on the program being consumed, binge-watching can significantly influence viewers' reception of the program. In another study, de Feijter and colleagues (2016) found the more episodes viewed in a single binge-watching session, the less viewers enjoyed the program, more they experienced guilt, and more they engaged in secondary activities such as eating, instant messaging, or using social media. As a consequence, they noted, "viewers might lose focus of substantial details of the story - dialogue and plot points - that are essential for the contemporary complex TV narratives" (de Feijter et al., 2016, p. 65). Ameri and colleagues (2017) further found though anime viewers reported enjoying binge-watched programs more, such behavior reduced their likelihood of producing their own content than if they had watched the program over more time. This suggests viewers who binge-watch are less likely to be influenced by media content in ways viewers are known to be influenced when engaging in one-episode-per-week viewing, or what Matrix (2014) called "appointment viewing." Therefore, we hypothesize

H4: participants who consume the television program on an appointment-viewing schedule will exhibit lower levels of prejudice against the depicted social out-group postexposure than those who consume the program in a single binge-watching session.

Moreover, recent research by Warren (2016) and Devasagayam (2014) has investigated the relationship between binge-watching behavior and elements of narrative and character involvement previously discussed. Specifically, Devasagayam (2014) found the vast majority of participants formed parasocial relationships with characters in programs they binge-watched, while Warren (2016) found binge-watching significantly increased viewers' levels of transportation. As such, if narrative and character involvement increase the effects of fictional narratives, and if binge-watching increases narrative and character involvement, we might expect

H5: the relationship between viewing schedule (appointment-viewing vs. binge-watching) and levels of prejudice against the depicted social out-group postexposure will be mediated by levels of narrative and character involvement.

Yet while it seems clear binge-watched programs should yield lesser effects on viewers' social attitudes in the short term (i.e., at Time 2), the question remains of whether - and if so, how - the long-term effects (i.e., at Time 3) of binge-watched television may differ from those of television consumed one-episode-per-week. Horvath, Horton, Lodge, and Hattie (2017) thus far offer the only clear evidence on this question, finding "although binge watching leads to strong memory formation immediately following program viewing, these memories decay more rapidly than memories formed after daily- or weekly-episode viewing schedules." Therefore, extending the implications of their findings, we hypothesize

H6: participants who consume the television program on an appointment-viewing schedule will exhibit more persistent attitudinal change toward the depicted social out-group 
group at Time 3 (three weeks after Time 2) than those who consume the program in a single binge-watching session.

It is important to note that because there is such a small extant literature on the effects of bingewatched television, these final three hypotheses $\left(\mathrm{H}_{4}-\mathrm{H}_{6}\right)$ are somewhat speculative. That is to say, these hypotheses are based on the findings and logical implications of the few (and methodologically limited) studies available, rather than reflective of clear patterns or explanatory mechanisms found in a more extensive literature. Because of the limitations of existing studies, the present study aims to firmly establish whether the hypothesized effects occur as a baseline from which to launch further studies probing the precise causal mechanisms.

\section{Method}

\subsection{Stimulus: Amazon's Transparent}

Amazon Prime, one of the three largest online streaming services, aired the half-hour comedydrama program Transparent from 2014 to 2019, which was delivered to viewers in full-series batches annually (with the exception of the final season). Transparent tells the story of the Pfefferman family, which is dealing with the recent revelation that the family's patriarch, Maura (ne Mort, played by Jeffrey Tambor), is a transgender woman. Participants were exposed to the first six episodes of the first series of Transparent (six half-hour episodes for a total of three hours) online, either in one continuous three-hour session (binge-watching) or in six half-hour sessions, each separated by roughly seven days (appointment-viewing). Across these six episodes, Maura comes out to all three of her children, each of whom copes with the news in different ways, ranging from immediately accepting to highly resistant. She also runs into an old friend who is shocked by her transgender identity and she forms close friendships with two other transgender women. The show has been immensely popular among viewers (Tretbar, 2014), and has been highly critically acclaimed, winning two Golden Globe awards, three Critics' Choice awards, and eight Primetime Emmy awards as of the time of writing. ${ }^{1}$

\subsection{Participants}

Potential participants $(N=281$ ) were recruited from Amazon's Mechanical Turk (MTurk). Although some consider it a controversial sampling platform, scholars across various fields have convincingly demonstrated the reliability of results obtained from MTurk (Buhrmester et al., 2011; Berinsky et al., 2012; Paolacci \& Chandler, 2014; Rand, 2012). For example, Berinsky, Huber, and Lenz (2012) found MTurk workers are more representative of the U.S. population than convenience samples found offline and far more representative than the "college sophomore" convenience sample often relied upon for social science research. Moreover, they replicated the findings of three gold standard studies that each used different types of samples (Internet panel, in-person convenience, and face-to-face survey) using an MTurk sample. In the present study, the mean participant age was nearly 40 with a range of 21 to 69 , thus offering a much more representative sample - and one whose pre-exposure attitudes toward transgender people were less likely to skew positive - than if an undergraduate sample had been employed.

\footnotetext{
${ }^{1}$ It is important to note that the show came to a hasty ending because of numerous scandals involving Jeffrey Tambor, the actor who portrayed the transgender lead character, Maura. Specifically, he was accused of serial sexual harassment by his personal assistant, Van Barnes, and one of his costars, Trace Lysette, both of whom are transgender women. He was subsequently fired from the show's fifth series, which was announced to be its last (Goldberg, 2018). However, the present study was conducted from June to August 2016, between the release of the second and third series of the show and over a year prior to the first public accusation against Tambor. Thus, the scandal cannot have impacted participants' perceptions of the show or the character of Maura.
} 
Participants were offered modest financial compensation for participation in the full study; those who dropped out of the study were paid a prorated amount. Those who had previously viewed one or more episodes of Transparent were excluded from participation. Of those who responded to the solicitation for participants, $251(89 \%)$ were both eligible to participate and chose to do so. Potential participants were then randomly assigned into one of two groups - an appointmentviewing group $(n=129)$ or a binge-watching group $(n=122)$. Due to concerns about attrition in the appointment-viewing group, in which participants would need to return once per week, we deliberately oversampled. While we did not need to oversample for the binge-watching group, we needed to ensure true random assignment to condition (i.e., $50 \%$ chance of being placed in either group), so we sampled evenly into both groups. Not doing so would have meant the odds of being placed into the appointment-viewing group would have been significantly higher for all participants than the odds of being placed into the binge-watching group. However, since we did not need all 122 participants in the condition, 60 were randomly selected from the pool assigned to the bingewatching condition for invitation to participate in the full study. Of the 189 participants invited to participate across both groups, $92 \%$ began the study, resulting in a total starting participant pool of $N=174$. Of those participants, $60 \%$ completed the experiment, resulting in a final sample of $N$ $=105$ valid cases $(n=69$ from the appointment-viewing group and $n=36$ from the binge-watching group).

While we cannot be certain the reason attrition was higher than expected among binge-watching participants and lower than expected among appointment-viewing participants, we can offer some reasonable conjecture. Regarding the binge-watching group, because participants agreed to their viewing condition six weeks before actually participating in the study, they may have agreed without fully considering their schedule or may have filled their schedules with conflicts in the intervening time, forgetting their agreement to participate. As for the appointment-viewing group, we strongly suspect participants ceased to drop from the study because they developed interest and investment in the program and genuinely wanted to continue watching. Indeed, several participants emailed to comment how much they enjoyed the show, with one participant writing, "I love this show! I can't wait till Fridays [the day weekly invites were sent out] just so I can watch the next one." Moreover, at the conclusion of the study several participants emailed to inform they would continue to watch the next series on their own time.

Participants were $54 \%$ female-identified $(n=57)$ and $46 \%$ male-identified $(n=48)$, none of whom further identified as transgender. The sample ranged in age from 21 to $69(M=38.99, S D=12.04)$. The majority of participants identified as White $(n=84,80 \%)$, while the remainder identified as Latino/Hispanic $(n=7,7 \%)$, Black/African American $(n=6,6 \%)$, Asian American/Pacific Islander $(n=4,4 \%)$, multi-racial $(n=3,3 \%)$, or American Indian/Alaska Native $(n=1,1 \%)$. Most participants identified as straight $(n=98,93 \%)$, with the remaining participants identifying as bisexual $(n=5,5 \%)$ or gay $(n=2,2 \%)$.

\subsection{Procedure}

Potential participants completed a screener questionnaire, which explained the project would entail viewing three hours of award-winning television on a personalized schedule over the course of six weeks and asked if they would be willing to participate in the study as described. Participants who indicated willingness were then directed to a subsequent page on which they were asked to check from a list of 12 programs distributed by Netflix, Hulu, or Amazon all the shows of which they had previously viewed one or more episodes. Those who had watched Transparent were excluded from participation.

Eligible participants $(N=251)$ were randomly assigned into experimental conditions as described above and messaged to inform them of their assigned viewing schedule. All sampled participants $(N$ 
$=187$ ) were then invited to complete a questionnaire consisting of standard demographic questions and measures of both familiarity with and attitudes toward transgender people and other social out-groups prior to exposure to the stimulus (Time 1). $N=174$ completed the questionnaire.

The next week, participants in the appointment-viewing condition $(n=114)$ were invited to view the first episode. Participants were sent invitations on Friday morning and had until Sunday night to complete their viewing. After viewing, participants answered two questions to ensure they viewed the program. Questions were chosen such that intense focus would not be required to remember the details of the answer, while the details would also not be found in summaries of the episodes online. Across the entire experiment, seven participants were terminated from the study for failing attention checks. Participants in the appointment-viewing condition repeated this process every week for six weeks.

Concurrent to the appointment viewers' final week, participants in the binge-watching condition $(n=60)$ were invited to watch all six episodes in one continuous session. Participants had five hours from beginning their viewing to finish, so as to ensure fidelity to the binge phenomenon. Like those in the appointment-viewing condition, participants in the binge-watching condition received invitations to begin viewing on Friday morning and had until Sunday night to finish. They likewise answered two questions to ensure viewing between each episode.

Immediately after viewing the sixth and final episode, remaining participants in both conditions ( $n=69$ from the appointment-viewing group and $n=36$ from the binge-watching group) completed a questionnaire reassessing attitudes toward transgender people, as well as assessing relevant narrative and character involvement variables (Time 2). Three weeks later, all remaining participants were invited to complete a final questionnaire reassessing attitudes toward transgender people (Time 3); $78 \%$ of participants ( $n=52$ from the appointment-viewing group and $n=30$ from the bingewatching group) completed this final questionnaire. Table 1 presents the timeline of events for the experimental procedure.

Table 1: Timeline of Experimental Procedure

\begin{tabular}{lcl}
\hline Appointment-viewing Condition & Week & Binge-watching Condition \\
\hline Pre-exposure questionnaire $(n=129)$ & 1 (Time 1) & Pre-exposure questionnaire $(n=58)$ \\
Episode 1 viewing $(n=114)$ & 2 & - \\
Episode 2 viewing & 3 & - \\
Episode 3 viewing & 4 & - \\
Episode 4 viewing & 5 & - \\
Episode 5 viewing & 6 & - \\
Episode 6 viewing + post-exposure & 7 (Time 2) & Episode 1-6 viewing + post-exposure \\
questionnaire $(n=69)$ & 8 & questionnaire $(n=36)$ \\
- & 9 & - \\
Post-exposure questionnaire $(n=52)$ & 10 (Time 3) & Post-exposure questionnaire $(n=30)$ \\
\hline
\end{tabular}

\subsection{Measures}

All measures took the form of seven-point Likert-type scales, except where otherwise stated, though response labels differed depending on the construct. For all scales, greater scores indicate greater magnitudes of the construct. In addition to the traditional Cronbach's alpha, scale reliabilities were assessed via hierarchical omega, which offers a more robust assessment of scale reliability and internal consistency (Peters, 2014). 
Prejudice toward transgender people. To measure prejudice toward transgender people, we adapted the five-item revised short form of the Attitudes Toward Lesbians and Gay Men scale (Herek \& McLemore, 2011), rewriting measures to ask about transgender people (e.g., "I think male-to-female transgender people are disgusting" and "Male-to-female transgenderism is merely a different kind of lifestyle that should not be condemned."). Two items related to sexual intercourse were dropped because of their irrelevance. Items were averaged to form a single factor and tested for reliability $\left(\alpha=.97, \omega_{h}=.89\right) .^{2}$

While test sensitization was a concern because the same measure was employed at three different points in the study, we feel confident in our measurements for a few reasons. First, at their closest, measurements were three weeks apart, making it unlikely that participants remembered the specifics of the questionnaire items. Second, because participants were MTurk workers, they participate in such a large volume of activities (including studies) that it would be difficult for them to maintain enough mental distinction between tasks that they would be sensitized to the measure. Finally, we embedded the items measuring prejudice toward transgender people in a set of distractor items about various prejudices, including toward Jewish people, gays and lesbians, and Black Americans.

Parasocial relationship. Parasocial relationship with the transgender main character, Maura, was measured using an adaptation of Rubin and Perse's (1987) 10-item Parasocial Interaction Scale. Sample items included, "Maura makes me feel comfortable, as if I am with a friend" and "I would like to meet Maura in person." One item concerning missing the character when they are not in an episode was dropped because Maura is in every episode. Items were averaged and tested for reliability $\left(\alpha=.92, \omega_{h}=.83\right)$.

Identification. Identification with Maura was measured using Tal-Or and Cohen's (2010) fiveitem adaptation of Cohen's (2001) original scale. Items were mildly adapted to suit the current study. For example, "I understood the events in the movie the way Jack understood them" was adapted to read, "I understood the events in the television program the way Maura understood them." Items were averaged and tested for reliability $\left(\alpha=.91, \omega_{h}=.85\right)$.

Perceived similarity. Following Tian and Hoffner (2010), similarity to Maura was measured using five items from Auter and Palmgreen's (2000) Audience-Persona Interaction Scale. Sample items included, "Maura reminds me of myself" and "I seem to have the same beliefs or attitudes as Maura." Items were averaged and tested for reliability $\left(\alpha=.86, \omega_{h}=.68\right)$.

Liking. Liking of Maura was measured using Dibble and Rosaen's (2011) seven-item scale. Sample items included, "I like Maura" and "I have no respect for Maura." Items were averaged and tested for reliability $\left(\alpha=.93, \omega_{h}=.87\right)$.

Transportation. Transportation into the narrative was measured using six items adopted from Green and Brock's (2000) transportation scale. Sample items included, "I was mentally involved in the television program while watching it" and "I could picture myself in the scene of the events portrayed in the television program." Items were averaged and tested for reliability $\left(\alpha=.85, \omega_{h}=\right.$ $.80)$.

Enjoyment. Following Chung and Slater (2013), enjoyment of the narrative was measured using five items on a seven-point semantic differential scale and three items on a seven-point Likert-type scale. Items were averaged and tested for reliability $\left(\alpha=.98, \omega_{h}=.96\right)$.

\footnotetext{
${ }^{2}$ This study was conducted prior to the publication of the Attitudes Toward Transgender Men and Women (ATTMW) scale (Billard, 2018), which would have been a more appropriate measure.
} 


\section{Results}

\subsection{Preliminary Analyses}

To ensure successful random assignment to the experimental conditions, we ran a series of chi-squares and $t$-tests on demographic and pre-exposure prejudice measures. As shown in Table 2, there were no statistically significant differences between groups on any measure. Thus, random assignment to the conditions was successful and the differences in experimental group size caused by lack of expected attrition among appointment-viewing participants did not produce significant differences on any research or control variables.

Table 2: Means (Standard Deviations) and Percentages for Demographics and Pre-exposure Prejudice

\begin{tabular}{|c|c|c|c|c|}
\hline \multirow[b]{2}{*}{ Variable } & \multicolumn{2}{|c|}{ Condition } & \multirow[b]{2}{*}{$t(103) / \chi^{2}$} & \multirow[b]{2}{*}{$p$} \\
\hline & $\begin{array}{l}\text { Appointment-viewing } \\
\quad(n=69)\end{array}$ & $\begin{array}{l}\text { Binge-watching } \\
\quad(n=36)\end{array}$ & & \\
\hline Age & $39.0(12.48)$ & $39.0(11.31)$ & -0.01 & 0.995 \\
\hline Gender (Female) & $57 \%$ & $50 \%$ & 0.41 & 0.524 \\
\hline Sexual orientation & & & 1.12 & 0.57 \\
\hline Straight & $93 \%$ & $94 \%$ & & \\
\hline Gay & $3 \%$ & $0 \%$ & & \\
\hline Bisexual & $4 \%$ & $6 \%$ & & \\
\hline Race/Ethnicity & & & 5.14 & 0.4 \\
\hline White & $83 \%$ & $75 \%$ & & \\
\hline Latino/Hispanic & $7 \%$ & $6 \%$ & & \\
\hline Black/African American & $6 \%$ & $6 \%$ & & \\
\hline Asian American/Pacific Islander & $2 \%$ & $8 \%$ & & \\
\hline Multi-racial & $2 \%$ & $6 \%$ & & \\
\hline American Indian/Alaska Native & $2 \%$ & $0 \%$ & & \\
\hline Prejudice toward trans people & $2.44(1.52)$ & $2.87(1.83)$ & -1.29 & 0.2 \\
\hline
\end{tabular}

Note. The third column present chi-squares for categorical variables and t-tests for continuous variables. For $t$-tests, Levene?s tests were conducted and indicated equal variances between groups. Not all categorical variables sum to $100 \%$ due to rounding.

\subsection{Hypothesis Testing}

The first hypothesis (H1) predicted exposure to a social-outgroup character would reduce prejudice against members of that group, regardless of condition. A paired samples $t$-test revealed a significant difference in levels of anti-transgender prejudice between Time $1(M=2.58, S D=1.64)$ and Time 2 $(M=2.18, S D=1.32), t(104)=4.30, \mathrm{p}<.001,95 \%$ Confidence Interval $(\mathrm{CI})[0.22,0.60]$, Cohen's $d=.27$. Thus, as post-exposure levels of prejudice were significantly lower than pre-exposure levels, $H 1$ was fully supported.

Together, H2 and H3 predicted experiencing greater parasocial relationship, identification, perceived similarity, liking, transportation, and enjoyment would result in lower levels of post-exposure prejudice. To test these hypotheses, we conduct an ordinary least squares (OLS) regression with prejudice at Time 2 as the dependent variable; parasocial relationship, narrative involvement, and character involvement variables as independent variables; and pre-exposure prejudice as a control variable. As indicated in Table 3, parasocial relationship with Maura was a nonsignificant predictor 
of prejudice, as were both the narrative involvement variables. Liking of Maura was a statistically significant predictor $(\beta=-0.42, p<.001)$ such that greater liking was associated with less post-exposure prejudice, while each of the other character involvement variables was nonsignificant. Therefore, H2 was not supported, while $H 3$ was partially supported.

Table 3: Summary of Regression Analysis for Variables Predicting Post-Exposure (Time 2) Prejudice $(N=105)$

\begin{tabular}{|c|c|c|c|}
\hline Variable & $\beta$ & $b(S E)$ & $95 \%$ CI \\
\hline \multicolumn{4}{|c|}{ Block 1: Narrative and Character Involvement } \\
\hline PSR with Maura & 0.02 & $0.02(0.13)$ & {$[-0.24,0.29]$} \\
\hline Identification with Maura & -0.03 & $-0.03(0.09)$ & {$[-0.21,0.15]$} \\
\hline Perceived similarity to Maura & -0.07 & $-0.08(0.08)$ & {$[-0.24,0.07]$} \\
\hline Liking of Maura & $-0.42^{* * *}$ & $-0.52(0.13)$ & {$[-0.77,-0.26]$} \\
\hline Transportation into program & -0.1 & $-0.13(0.11)$ & {$[-0.35,0.09]$} \\
\hline Enjoyment of program & 0.15 & $0.14(0.09)$ & {$[-0.04,0.33]$} \\
\hline$\Delta$ Adjusted $R^{2}$ & & $.52^{* * *}$ & \\
\hline \multicolumn{4}{|c|}{ Block 2: Pre-Exposure (Time 1) Prejudice } \\
\hline Prejudice toward transgender people & $0.59 * * *$ & $0.47(0.04)$ & {$[0.39,0.56]$} \\
\hline$\Delta$ Adjusted $R^{2}$ & & $.26^{* * *}$ & \\
\hline Total Adjusted $R^{2}$ & & $.78^{* * *}$ & \\
\hline
\end{tabular}

$H_{4}$ predicted participants who consumed the television program on an appointment-viewing schedule would exhibit less post-exposure prejudice against members of the depicted social-outgroup than those who consumed the program on a binge-watching schedule. To examine differences across time between the conditions, we first conducted independent samples $t$-tests comparing postexposure prejudice between groups at Time 2 and at Time 3. Because Levene's tests for equality of variances indicated unequal variances between the groups at both post-exposure measurement times, we employed Welch's $t$-test rather than Student's $t$-test. Results indicated prejudice levels in the binge-watching condition $(M=2.56, S D=1.59)$ and appointment-viewing condition $(M=$ $1.98, S D=1.12)$ at Time 2 were not significantly different, $t(53.52)=-1.94, p=.058,95 \%$ CI $[-1.17$, 0.02]. However, at Time 3 , the difference between prejudice levels in the binge-watching condition $(M=3.22, S D=1.81)$ and appointment-viewing condition $(M=2.22, S D=1.13)$ was statistically significant, $t(42.17)=-2.73, p=.009,95 \%$ CI [-1.74, -0.26], Cohen's $d=.66$.

Next, we conducted a repeated measures analysis of variance (ANOVA) with measurement time (Time 1, Time 2, Time 3) as the within-subjects variable and condition (appointment-viewing vs. binge-watching) as the between-subjects variable. Analysis revealed a significant main effect of time on prejudice toward transgender people, $F(2,79)=9.02, p<.001, \eta^{2}=.19$. In addition, there was a significant between-subjects effect such that participants in the appointment-viewing condition exhibited less prejudice than those in the binge-watching condition, $F(1,80)=7.01, p=0.01, \eta^{2}$ $=.08$. There was no significant interaction effect, $F(2,79)=1.79, p=.173$. Taking the results of these tests together, $H_{4}$ was supported.

H5 predicted narrative and character involvement measures would mediate the relationship between viewing condition and levels of post-exposure prejudice. To test this hypothesis, we ran two conditional process analyses using ordinary least squares regression models and a bootstrap estimation of 10,000 samples (Hayes, 2013). These analyses offer bootstrap estimates of mediated effects with $95 \%$ CI. In the first analysis, post-exposure prejudice at Time 2 was the dependent variable, 
while condition was the independent variable and narrative and character involvement variables were included as mediators. As show in Figure 1, narrative and character involvement variables were all significantly predicted by condition such that participants in the appointment-viewing condition experienced each more strongly. However, in turn, only liking of Maura $(B=-0.86, p<.001)$ and enjoyment of the program $(B=0.30, p<.05)$ were significant predictors of prejudice. Thus, in addition to the main effect of condition on post-exposure prejudice $(B=0.58, p<.05)$, only liking and enjoyment mediated the relationship between condition and outcome at Time 2 .

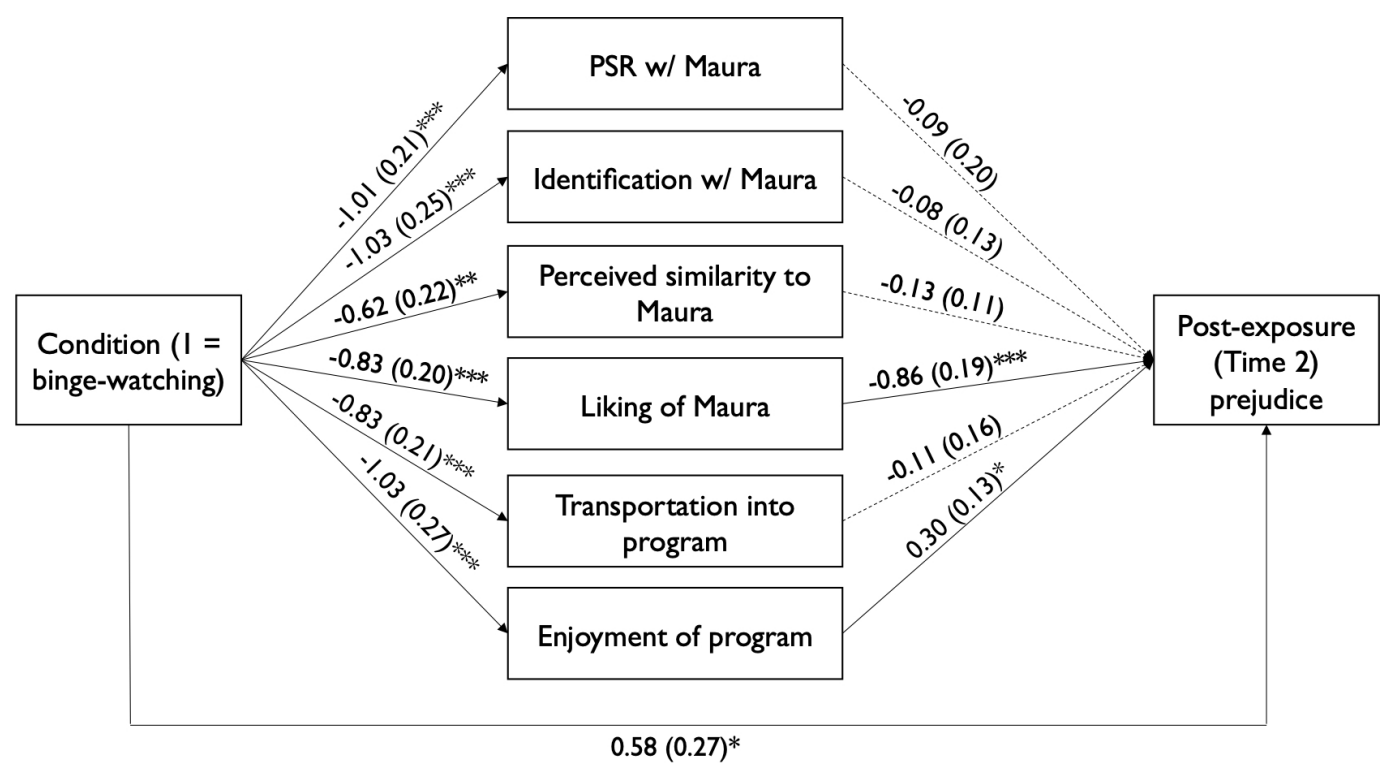

Figure 1: Unstandardized regression coefficients (and standard errors) for the effect of viewing condition on Time 2 prejudice toward transgender people as mediated by narrative and character involvement. Note: ${ }^{*} p<.05 .{ }^{* *} p<.01 .{ }^{* * *} p<.001$.

In the second analysis, post-exposure prejudice at Time 3 was the dependent variable. As show in Figure 2, again narrative and character involvement variables were all significantly predicted by condition such that participants in the appointment-viewing condition experienced each more strongly. In this case, however, none of the narrative or character involvement variables significantly predicted prejudice. Thus, there was a main effect of condition on post-exposure prejudice $(B=$ $1.00, p<.01$ ), but the relationship between condition and outcome was not mediated by narrative and character involvement at Time 3. Taking these results together, H5 was not supported.

Finally, $H 6$ predicted viewers in the appointment-viewing condition would exhibit more persistent attitude change than those in the binge-watching condition. Further probing the observed betweensubjects effect (condition), a test of within-subjects contrasts revealed a non-linear quadratic pattern such that prejudicial attitudes at Time 2 decreased for participants in both groups, but the effect diminished entirely for participants in the binge-watching condition and only partially for participants in the appointment-viewing condition at Time 3 . Figure 2 presents this quadratic trend, $F(1$, $80)=17.85, p<.001, \eta^{2}=.182$. Therefore, $H 6$ was fully supported. 


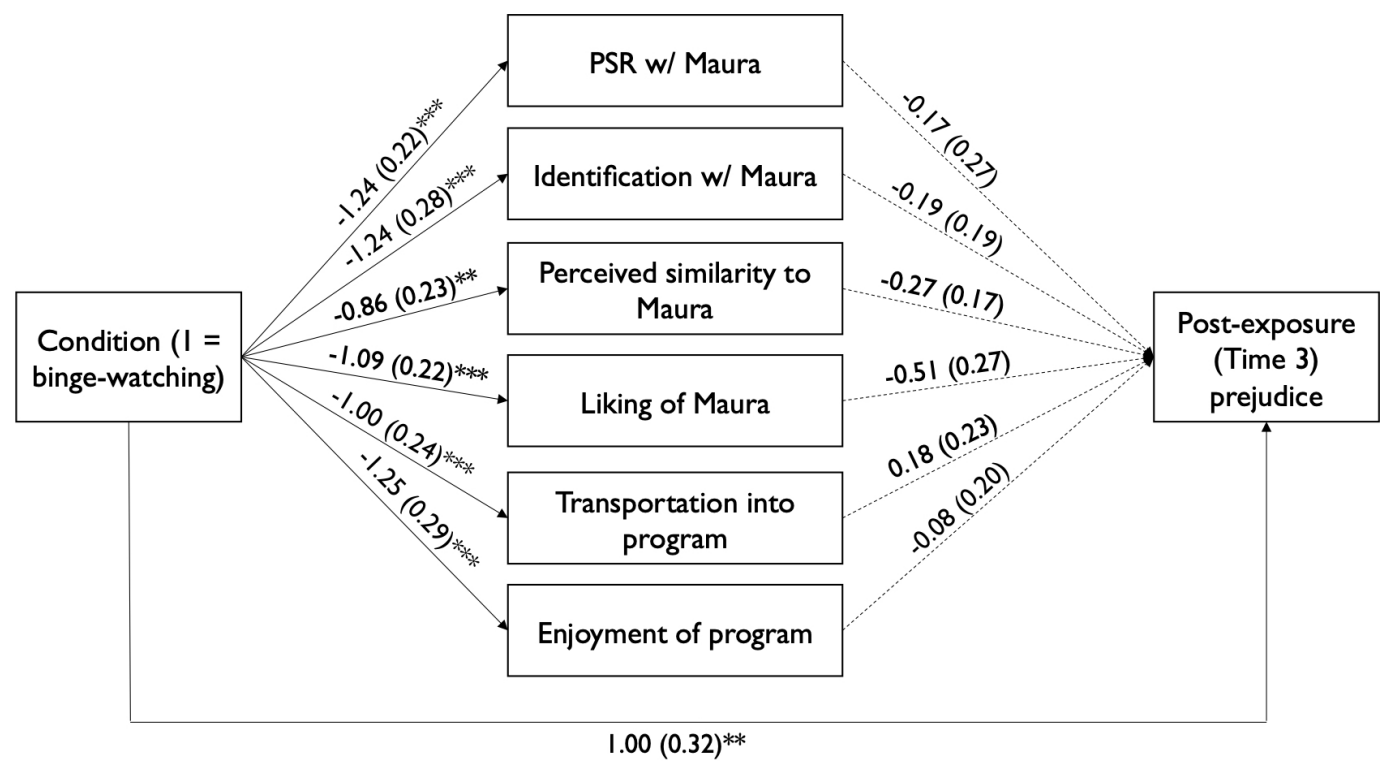

Figure 2: Unstandardized regression coefficients (and standard errors) for the effect of viewing condition on Time 3 prejudice toward transgender people as mediated by narrative and character involvement. Note: ${ }^{*} p<.05 .{ }^{* *} p<.01 .{ }^{* * *} p<.001$.

\section{Discussion}

With the advent of online streaming services, binge-watching has emerged as a dominant mode of television consumption. However, little work has investigated how the effects of binge-watched television might differ from those of television consumed on the traditional appointment-viewing schedule. The present study was designed to fill that gap, assessing how the prosocial effects of television media differ in the context of prejudice toward transgender people. In our experimental study we found that, regardless of viewing schedule, exposure to the fictional narrative reduced anti-transgender prejudice among participants. Moreover, post-exposure prejudice levels differed by experimental condition such that participants in the appointment-viewing condition exhibited less prejudice. Most significantly, however, the reduction in prejudice caused by exposure to the narrative persisted three weeks after viewing for those in the appointment-viewing condition, while it dissipated entirely for those in the binge-watching condition. Thus, we offer clear early evidence that binge-watched television does not produce the same prosocial effects as television consumed on an appointment-viewing schedule. Below we unpack these and other findings, discussing their theoretical implications.

Consistent with prior studies of the influence of fictional narratives on social attitudes and beliefs (e.g., Bond \& Compton, 2015; Chung \& Slater, 2013; Hoffner \& Cohen, 2012), and confirming our first hypothesis, viewing Transparent caused significant decreases in prejudice against transgender people. These results thus offer further evidence in support of the parasocial contact/mediated intergroup contact hypothesis, which maintains that exposure to fictional narratives depicting social out-group characters positively influences attitudes toward that group generally (Joyce \& Harwood, 2014; Ortiz \& Harwood, 2007; Schiappa et al., 2005, 2006). However, the strength of parasocial relationship developed with Maura did not predict the magnitude of prejudice reduction, as prior work indicated should be the case (e.g., Hoffner \& Cohen, 2012). This suggests, at least in certain 


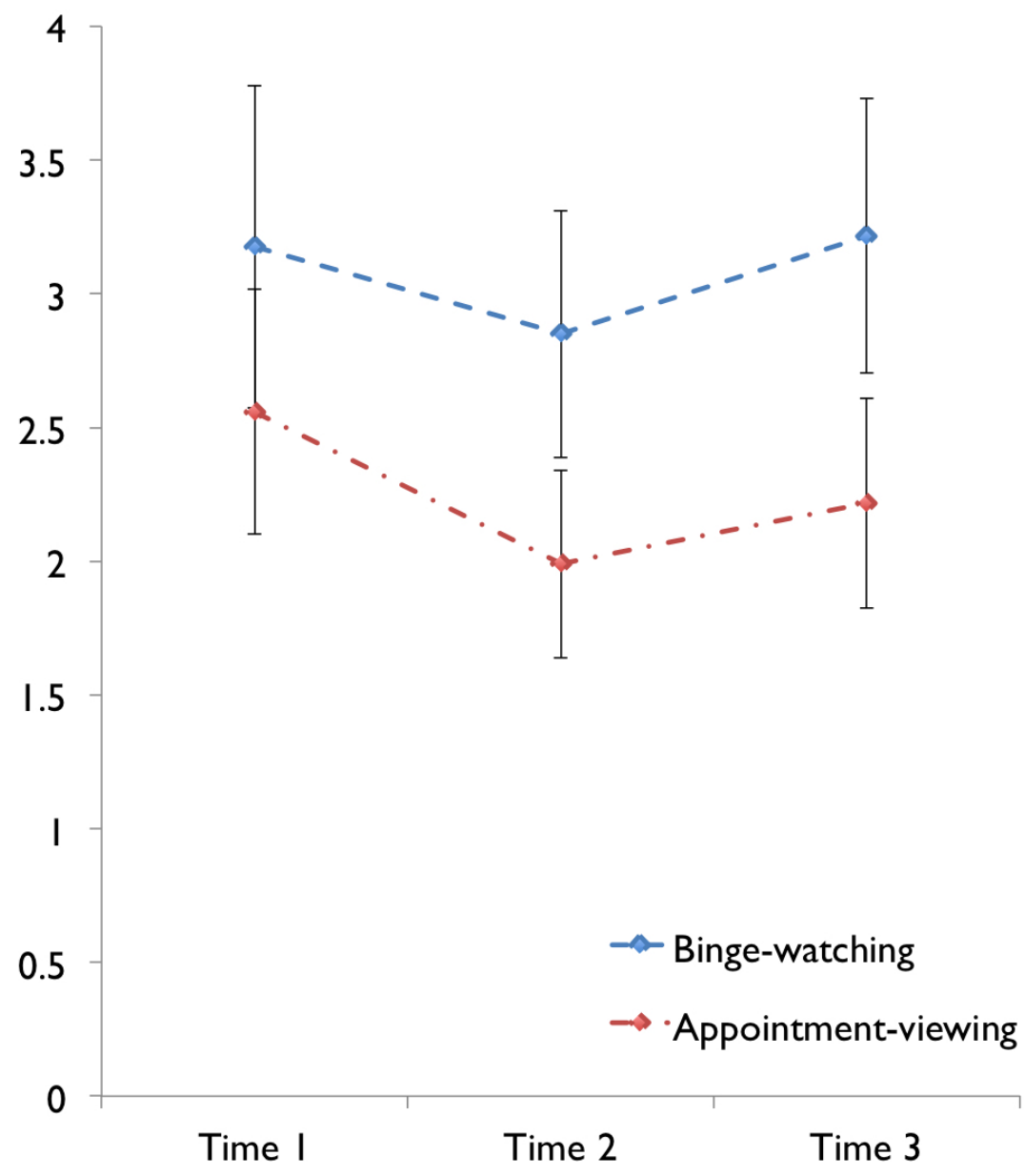

Figure 3: Quadratic trend in levels of prejudice toward transgender people over time by condition. 
contexts, mere exposure to social out-group members is enough to influence attitudes, which, indeed, other research on anti-transgender prejudice has found (Flores et al., 2017).

Likewise, counter to the predictions of E-ELM (Slater \& Rouner, 2002) and EORM (Moyer-Gus, 2008), most measures of narrative and character involvement - specifically, identification with the character, perceived similarity to the character, transportation into the narrative, and enjoyment of the program - did not predict post-exposure prejudice levels; only liking the character of Maura was associated with decreased prejudice. While liking Maura and enjoyment of the program mediated the relationship between condition and post-exposure prejudice at Time 2, no narrative or character involvement variables mediated this relationship at Time 3. Though these results contradict the E-ELM and EORM models, as well as empirical research supporting them (e.g., Moyer-Gus \& Nabi, 2010; Slater et al., 2006), they confirm the findings of other research, such as work by Jensen and colleagues (2011), who found identification and transportation did not predict delayed media effects. Furthermore, that liking and enjoyment mediated the relationship between viewing schedule and post-exposure prejudice in the immediate post-test but not the delayed post-test indicates perhaps narrative and character involvement influence attitudes during the viewing process, but not in the processes of information processing, storage, and retrieval. These results thus call into question both the E-ELM and EORM models, suggesting perhaps other mechanisms are at play in the process of fictional narrative persuasion.

Indeed, our findings regarding the differential effects of binge-watching and appointment-viewing indicate the original ELM (Petty \& Cacioppo, 1986) may be a more accurate model. Although EELM (Slater \& Rouner, 2002) and supporting research (Appel \& Richter, 2007) maintains fictional narratives are not processed in the same way as other persuasive messages, and thus dual-process models such as ELM (Petty \& Cacioppo, 1986) do not explain their effects, the original ELM does offer evidence that the effects of binge-watched television may differ from appointment-viewed television.

In its original formulation, ELM argues persuasion (i.e. attitudinal change) is arrived at by one of two routes: central or peripheral (Briol \& Petty, 2015; Petty \& Cacioppo, 1986). Whereas the central route involves active cognitive deliberation that situates experience and knowledge to determine an argument's merits, the peripheral route relies on heuristic cues and identification with the information source to determine (without deliberation) whether the persuasive argument is acceptable (Briol \& Petty, 2015; Petty et al., 2009). However, because attitudes arrived at via peripheral routes rely on more ephemeral mechanisms (e.g., emotional states, feelings about sources), they are also more easily undermined in the long term (Petty et al., 2009). In contrast, attitudes arrived at via central routes are more likely to persist because the mechanisms of deliberation more thoroughly incorporate persuasive information into one's cognitive structure (Haugtvedt \& Petty, 1992; Petty et al., 1995). In the context of prejudicial attitudes, research by Crdaba and colleagues (2013, 2014) demonstrated, though reductions in prejudice were arrived at via both central and peripheral routes, those arrived at by central routes were more persistent over time.

Slater and Rouner (2002) suggested that in the context of fictional narratives "a clean distinction between central and peripheral processes is no longer discernable" (p. 177) because absorption into narratives mitigate the deliberative processes that permit counterarguing (i.e., persuasion resistance). Yet, by this logic, attitudinal changes caused by fictional narratives would always fail to persist because of the lack of deliberation, even though research in line with E-ELM has demonstrated this kind of attitudinal change does in fact persist, if not increase (Appel \& Richter, 2007). Thus, we must consider the possibility the delineation between central and peripheral persuasion might exist in narrative contexts, as well.

Indeed, we might see separate central and peripheral routes emerge in relation to viewing schedule. Specifically, the nature of binge-watching does not lend itself to central processing as it entails a 
kind of transportation in the narrative world that Slater and Rouner (2002) contended prohibits deliberation. Viewing one episode per week, alternatively, allows more time for deliberation (and even discussion) between episodes, which permits a central route to be taken. As Jensen and colleagues (2011) articulated in their "delay hypothesis," "the full impact of fictional narratives may be felt over time as bits and fragments of the message are disconnected and then activated out of their original context" (pp. 509-510). Moreover, de Feijter and colleagues (2016) offered evidence binge-watchers are more likely to engage in secondary behaviors while viewing, which would certainly limit viewers' ability (even if not motivation) to deliberate and incline them toward peripheral processing, whereas appointment-viewing encourages more focused attention that would encourage central processing.

The results of the present study certainly indicate some support for this model. First, consistent with the nascent literature on binge-watched television (Ameri et al., 2017; de Feijter et al., 2016; Pena, 2015; Schweidel \& Moe, 2016), participants in the appointment-viewing condition exhibited less prejudice than those in the binge-watching condition after exposure to Transparent. More significantly, however, we found participants in the appointment-viewing condition exhibited more persistent attitudinal change, whereas those in the binge-watching condition returned to preexposure prejudice levels three weeks after viewing the program. While these results do not offer direct evidence of ELM, they are consistent with the model, while contradicting competing models (E-ELM and EORM). Thus, taking the present findings along with Horvath et al.'s (2017) findings that binge-watching resulted in more rapid memory decay and psychological research indicating how condensed timeline studying ("cramming") produces weaker long-term learning than studying on a distributed timeline (Gluckman, Vlach, \& Sandhofer, 2014; Kornell, 2009; Kpper-Tetzel, 2015), we must reconsider the arguments presented by Appel and Richer (2007) and Slater and Rouner (2002), among others, that dual-process models such as ELM should not be applied to contexts of narrative persuasion. Rather, we might consider if, and if so how, such models might inform the effects of fictional narratives.

Finally, this study adds to a nascent, but rapidly expanding literature on contemporary media representations of transgender people (Billard, 2016, 2017, 2019b, 2019c; Capuzza \& Spencer, 2017) and their effects on public attitudes (Billard, 2019a; Gillig et al., 2017).

\subsection{Implications for Industry}

Beyond their theoretical implications, the results of this study have interesting implications for the entertainment industry and the effectiveness of industry diversity initiatives. Considering again that representations of most social out-groups are more frequent in programs found on online streaming services than on cable or network television (Smith et al., 2016) and that online streaming television is more frequently binge-watched than appointment-viewed (Schweidel \& Moe, 2016), our results suggest diverse representations are, ironically, currently more prevalent on platforms on which they are less effective at improving intergroup attitudes. This study's conclusion that weekly paced programs are important vectors of prejudice reduction suggest network and cable television producers should follow the example of online streaming services in increasing the representational diversity of their programs so as to lend their greater effectiveness to advancing social equality.

\subsection{Limitations and Future Directions}

Despite its significant theoretical and practical implications, the present study has several limitations that must be addressed in future work. First, the study has limited external validity because participants were incentivized to participate, we cannot be sure they would have chosen to watch the show without external influence. While the stimulus program is highly popular with a wide following (Tretbar, 2014) so many may have viewed the program for its popularity regardless of their 
preexisting feelings about transgender people or issues, we cannot overlook the fact that exposure and viewing schedule are both entirely self-selected in the real world.

Second, our experimental design lacked a control condition in addition to the two experimental conditions. While our results clearly indicate a difference in the effects of binge-watched versus appointment-viewed television programs, the lack of control group makes it impossible to know whether either condition produces effects significantly different than no exposure at all. Third, the heightened media visibility and political volatility surrounding transgender individuals during the run of this experiment may have influenced participants' changes in prejudice beyond their exposure to the stimulus. Similarly, if participants engaged in extensive discussion about the program or about transgender issues more broadly with family, friends, and/or peers, this may have influenced their reported prejudice levels and introduced error into the data.

Fourth, this study is merely an early experimental investigation of how the effects of bingewatched television may differ from those of television consumed one-episode-per-week. Particularly considering Pena's (2015) findings that "the effect of binge watching on viewer reception is contingent on the show" (p. 54), further studies are needed across television genres and programs depicting other social groups or issues to ensure the generalizability of these findings. Finally, our study did not directly test the mechanisms of ELM (e.g., deliberation) offered as a potential explanation of our findings. Thus, further studies explicitly measuring these mechanisms would be required to confirm our theoretical proposition that ELM explains the differential effects of binge-watching and appointment-viewing. 


\section{References}

Allport, G. W. (1954). The nature of prejudice. Cambridge, MA: Perseus Books.

Ameri, M., Honka, E., \& Xie, Y. (2017). The effects of binge-watching on media franchise engagement. Unpublished manuscript, University of Texas, Dallas, TX.

Appel, M., \& Richter, T. (2007). Persuasive effects of fictional narratives increase over time. Media Psychology, 10(1), 113-134. doi:10.108/15213260701301194

Auter, P. J., \& Palmgreen, P. (2000). Development and validation of a parasocial interaction measure: The audience-persona interaction scale. Communication Research Reports, 17(1), 79-89. doi:10.1080/08824090009388753

Bandura, A. (2009). Social cognitive theory of mass communication. In J. Bryant \& M. B. Oliver (Eds.), Media effects: Advances in theory and research (3rd ed., pp. 94-124). New York, NY: Routledge.

Berinsky, A. J., Huber, G. A., \& Lenz, G. S. (2012). Evaluating online labor markets for experimental research: Amazon.com's Mechanical Turk. Political Analysis, 20 (3), 351-368. doi:10.1093/pan/mpr057

Bernardin, M. (2018). How binge-watching has changed TV writing. The Hollywood Reporter. Retrieved from https://www.hollywoodreporter.com/news/has-binge-watching-changed-tv-writing-1118988

Billard, T. J. (2016). Writing in the margins: Mainstream news media representations of transgenderism. International Journal of Communication, 10, 4193-4218.

Billard, T. J., \& MacAuley, B. L. (2017). "It's a bird! It's a plane! It's a transgender superhero!": Transgender characters in Marvel, DC, and Image comics. In C. D. Reinhard \& C. J. Olson (Eds.), Heroes, heroines, and everything in between: Challenging gender and sexuality stereotypes in children's entertainment media (pp. 233-252). Lanham, MD: Lexington Books.

Billard, T. J. (2018). Attitudes toward transgender men and women: Development and validation of a new measure. Frontiers in Psychology, 9(387). doi:10.3389/fpsyg.2018.00387

Billard, T. J. (2019a). (No) shame in the game: The influence of pornography viewing on attitudes toward transgender people. Communication Research Reports, 36(1), 45-56. doi:10.1080/08824096.2018.1549539

Billard, T. J. (2019b). "Passing" and the politics of deception: Transgender bodies, cisgender aesthetics, and the policing of inconspicuous marginal identities. In T. Docan-Morgan (Ed.), Palgrave handbook of deceptive communication. New York, NY: Palgrave Macmillan.

Billard, T. J. 2019. Setting the transgender agenda: Intermedia agenda-setting in the digital news environment. Politics, Groups, and Identities, 7(1), 165-176. doi:10.1080/21565503.2018.1532302

Bond, B. J., \& Compton, B. L. (2015). Gay on-screen: The relationship between exposure to gay characters on television and heterosexual audiences' endorsement of gay equality. Journal of Broadcasting and Electronic Media, 59(4), 717-732. doi:10.1080/08838151.2015.1093485

Briol, P., \& Petty, R. E. (2015). Elaboration and validation processes: Implications for media attitude change. Media Psychology, 18(3), 267-291. doi:10.1080/15213269.2015.1008103

Buhrmester, M., Kwang, T., \& Gosling, S. D. (2011). Amazon's Mechanical Turk: A new source of inexpensive, yet high-quality, data. Perspectives on Psychological Science, 6(1), 3-5. doi:10.1177/1745691610393980

Capuzza, J. C., \& Spencer, L. G. (2017). Regressing, progressing, or transgressing on the small screen? Transgender characters on U.S. scripted television series. Communication Quarterly, 65 (2), 214-230. doi:10.1080/01463373.2016.1221438

Crdaba, M. A. M., Briol, P., Horcajo, J., \& Petty, R. E. (2013). The effect of need for cognition on the stability of prejudiced attitudes toward South American immigrants. Psicothema, 25(1), 73-78. doi:10.7334/psicothema2012.107 
Crdaba, M. A. M., Briol, P., Horcajo, J., \& Petty, R. E. (2014). Changing prejudiced attitudes by thinking about persuasive messages: Implications for resistance. Journal of Applied Social Psychology, 44(5), 343-353. doi:10.1111/jasp.12225

Chung, A. H., \& Slater, M. D. (2013). Reducing stigma and out-group distinctions through perspective-taking in narratives. Journal of Communication, 63(5), 894-911. doi:10.1111/jcom.12050

Cohen, J. (1997). Parasocial relations and romantic attraction: Gender and dating status differences. Journal of Broadcasting and Electronic Media, 41(4), 516-529. doi:10.1080/08838159709364424

Cohen, J. (2001). Defining identification: A theoretical look at the identification of audiences with media characters. Mass Communication and Society, 4(3), 245-264.

Cook, C. (2018). A content analysis of LGBT representation on broadcast and streaming television (Undergraduate thesis). University of Tennessee, Chattanooga, TN.

Corfield, J. (2017). Network vs. Netflix: A comparative content analysis of demographics across prime-time television and Netflix original programming (Master's thesis). University of South Carolina, Columbia, SC.

de Feijter, D., Khan, V.-J., \& van Gisbergen, M. (2016). Confessions of a ?guilty' couch potato: Understanding and using context to optimize binge-watching behavior. In TVX '16: Proceedings of the ACM International Conference on Interactive Experiences for TV and Online Video (pp. 59-67). New York: ACM.

de Graaf, A., Hoeken, H., Sanders, J., \& Beentjes, J. W. J. (2012). Identification as a mechanism of narrative persuasion. Communication Research, 39(6), 802-823. doi:10.1177/0093650211408594

Devasagayam, R. (2014). Media bingeing: A qualitative study of psychological influences. In D. DeLong, D. Edmiston, \& R. Hightower (Eds,), Once Retro, Now Novel Again: 2014 Annual Spring Conference Proceedings (pp. 40-44). Chicago, IL: Marketing Management Academy.

Dibble, J. L., \& Rosaen, S. F. (2011). Parasocial interaction as more than friendship: Evidence for parasocial interactions with disliked media figures. Journal of Media Psychology, 23(3), 122-132. doi:10.1027/1864-1105/a000044

Dibble, J. L., Hartman, T., \& Rosaen, S. F. (2016). Parasocial interaction and parasocial relationship: Conceptual clarification and a critical assessment of measures. Human Communication Research, 42(1), 21-44. doi:10.1111/hcre.12063

Eyal, K., \& Dailey, R. M. (2012). Examining relational maintenance in parasocial relationships. Mass Communication and Society, 15(5), 758-781. doi:10.1080/15205436.2011.616276

Eyal, K., \& Rubin, A. M. (2003). Viewer aggression and homophily, identification, and parasocial relationships with television characters. Journal of Broadcasting and Electronic Media, 47(1), $77-98$.

Flores, A. R., Haider-Markel, D. P., Lewis, D. C., Miller, P. R., Tadlock, B. L., \& Taylor, J. K. (forthcoming). Challenged expectations: Mere exposure effects on attitudes about transgender people and rights. Political Psychology. doi:10.1111/pops.12402

Giles, D. C. (2002). Parasocial interaction: A review of the literature and a model for future research. Media Psychology, 4(3), 279-305.

Gillig, T. K., Rosenthal, E. L., Murphy, S. T., \& Folb, K. L. (forthcoming). More than a media moment: The influence of televised storylines on viewers' attitudes toward transgender people and policies. Sex Roles. doi:10.1007/s11199-017-0816-1

Gluckman, M., Vlach, H. A., \& Sandhofer, C. M. (2014). Spacing simultaneously promotes multiple forms of learning in children's science curriculum. Applied Cognitive Psychology, 28(2), 266-273. doi: $10.1002 /$ acp.2997

Goldberg, Lesley. (2018). Jeffrey Tambor officially dropped from ?Transparent' in wake of harassment claims. The Hollywood Reporter. Retrieved from https://www.hollywoodreporter.com/live- 
feed/jeffrey-tambor-officially-fired-transparent-wake-harassment-claims-1085236

Green, M. C., \& Brock, T. C. (2000). The role of transportation in the persuasiveness of public narratives. Journal of Personality and Social Psychology, 79(5), 701-721. doi:10.1037/00223514.79.5.701

Green, M. C., Brock, T. C., \& Kaufman, G. F. (2004). Understanding media enjoyment: The role of transportation into narrative worlds. Communication Theory, 14(4), 311-327. doi:10.1111/j.14682885.2004.tb00317.x

Hartmann, T., \& Goldhoorn, C. (2011). Horton and Wohl revisited: Exploring viewers' experience of parasocial interaction. Journal of Communication, 61(6), 1004-1121. doi:10.1111/j.14602466.2011.01595.x

Hartmann, T., \& Klimmt, C. (2005). Ursachen und Effekte parasozialer Interaktionen im Rezeptionsprozess: Eine Fragebogenstudie auf der Basis des PSI-Zwei-Ebenen-Modells [Causes and consequences of parasocial interaction in the reception process: A survey study based on a bilevel PSI model]. Zeitschrift Fr Medienpsychologie, 17(3), 88-98. doi:10.1026/1617-6383.17.3.88

Haugtvedt, C. P., \& Petty, R. E. (1992). Personality and persuasion: Need for cognition moderates the persistence and resistance of attitude changes. Journal of Personality and Social Psychology, 63(2), 308-319. doi:10.1037/0022-3514.63.2.308

Hayes, A. F. (2013). Introduction to mediation, moderation, and conditional process analysis: A regression-based perspective. New York, NY: Guilford Press.

Herek, G. M., \& McLemore, K. A. (2011). Attitudes Toward Lesbians and Gay Men Scale. In T. D. Fisher, C. M. Davis, \& W. L. Yarber (Eds.), Handbook of sexuality-related measures (3rd ed., pp. 415-417). New York, NY: Routledge.

Hoffner, C., \& Buchanan, M. (2005). Young adults' wishful identification with television characters: The role of perceived similarity and character attributes. Media Psychology, 7(4), 325-351.

Hoffner, C., \& Cantor, J. (1991). Perceiving and responding to mass media characters. In J. Bryant \& D. Zillmann (Eds.), Responding to the screen: Reception and reaction processes (pp. 63-101). Hillsdale, NJ: Lawrence Erlbaum.

Hoffner, C., \& Cohen, E. L. (2012). Responses to obsessive compulsive disorder on Monk among series fans: Parasocial relations, presumed media influence, and behavioral outcomes. Journal of Broadcasting and Electronic Media, 56(4), 650-668. doi:10.1080/088381S1.2012.732136

Horton, D., \& Wohl, R. R. (1956). Mass communication and para-social interaction: Observations on intimacy at a distance. Psychiatry, 19(3), 215-229.

Horvath, J. C., Horton, A. J., Lodge, J. M., \& Hattie, J. A.C. (2017). The impact of binge watching on memory and perceived comprehension. First Monday, 22(9). doi:10.5210/fm.v22i19.7729

Jenner, M. (2016). Is this TVIV? On Netflix, TVIII and binge-watching. New Media $\mathcal{E}$ Society, 18(2), 257-273. doi:10.1177/1461444814541523

Jensen, J. D., Bernat, J. K., Wilson, K. M., \& Goonewardene, J. (2011). The delay hypothesis: The manifestation of media effects over time. Human Communication Research, 37(4), 509-528. doi:10.1111/j.1468-2958.2011.01415.x

Joyce, N., \& Harwood, J. (2014). Improving intergroup attitudes through televised vicarious intergroup contact: Social cognitive processing of ingroup and outgroup information. Communication Research, 41(5), 627-643. doi:10.1177/0093650212447944

Klimmt, C., Hartmann, T., \& Schramm, H. (2006). Parasocial interactions and relationships. In J. Bryant \& P. Vorderer (Eds.), Psychology of entertainment (pp. 291-313). Mahwah, NJ: Lawrence Erlbaum.

Kornell, N. (2009). Optimising learning using flashcards: Spacing is more effective than cramming. Applied Cognitive Psychology, 23(9), 1297-1317. doi:10.1002/acp.1537 
Kpper-Tetzel, C. E. (2014). Understanding the distributed practice effect: Strong effects on weak theoretical grounds. Zeitschrift fr Psychologie, 222 (2), 71-81. doi:10.1027/2151-2604/a000168

Mangelschots, E. (2017). De parasociale contacthypothese: De rol van sociaal en parasociaal contact in het benvloeden van vooroordelen, stereotypes en negatieve attitudes ten aanzien van transgenders [The parasocial contact hypothesis: The role of social and parasocial contact in influencing prejudice, stereotypes, and negative attitudes toward transgender people] (Master's thesis). KU Leuven, Leuven, Belgium.

Matrix, S. (2014). The Netflix effect: Teens, binge watching, and on-demand digital media trends. Jeunesse: Young People, Texts, Cultures, 6(1), 119-138. doi:10.1353/jeu.2014.0002

Morning Consult. (2018a). Most young adults have an appetite for binge-watching shows. Morning Consult. Retrieved from https://morningconsult.com/2018/11/06/most-young-adults-have-anappetite-for-binge-watching-shows /

Morning Consult. (2018b). Share of adults who subscribe to a streaming service in the United States as of October 2018. Statista. Retrieved from https://www.statista.com/statistics/325162/svodpenetration-rate/

Moyer-Gus, E. (2008). Toward a theory of entertainment persuasion: Explaining the persuasive effects of entertainment-education messages. Communication Theory, 18(3), 407-425. doi:10.1111/j.1468-2885.2008.00328.x

Moyer-Gus, E., \& Nabi, R. L. (2010). Explaining the effects of narrative in an entertainment television program: Overcoming resistance to persuasion. Human Communication Research, 36(1), 26-51. doi:10.1111/j.1468-2958.2009.01367.x

Murphy, S. T., Frank, L. B., Moran, M. B., \& Patnoe-Woodley, P. (2011). Involved, transported, or emotional? Exploring the determinants of change in knowledge, attitudes, and behavior in entertainment-education. Journal of Communication, 61(3), 407-431. doi:10.1111/j.14602466.2011.01554.x

Ortiz, M., \& Harwood, J. (2007). A social cognitive theory approach to the effects of mediated intergroup contact on intergroup attitudes. Journal of Broadcasting and Electronic Media, 51(4), 615-631. doi:10.1080/08838150701626487

Paolacci, G., \& Chandler, J. (2014). Inside the Turk: Understanding Mechanical Turk as a participant pool. Current Directions in Psychological Science, 23(3), 184-188. doi:10.1177/0963721414531598

Pena, L. L. (2015). Breaking binge: Exploring the effects of binge watching on television viewer reception (Master's thesis). Syracuse University, Syracuse, NY.

Peters, G.-J. Y. (2014). The alpha and the omega of scale reliability and validity: Why and how to abandon Cronbach's alpha and the route towards more comprehensive assessment of scale quality. The European Health Psychologist, 16(2), 56-69.

Petty, R. E., Briol, P., \& Priester, J. R. (2009). Mass media attitude change: Implications of the elaboration likelihood model of persuasion. In J. Bryant \& M. B. Oliver (Eds.), Media effects: Advances in theory and research (3rd ed., pp. 125-164). New York, NY: Routledge.

Petty, R. E., \& Cacioppo, J. T. (1986). Communication and persuasion: Central and peripheral routes to attitude change. New York, NY: Springer.

Petty, R. E., Haugtvedt, C. P., \& Smith, S. M. (1995). Elaboration as a determinant of attitude strength: Creating attitudes that are persistent, resistant, and predictive of behavior. In R. E. Petty \& J. A. Krosnick (Eds.), Attitude strength: Antecedents and consequences (pp. 93-130). Mahwah, NJ: Lawrence Erlbaum.

Pittman, M., \& Sheehan, K. (2015). Sprinting a media marathon: Uses and gratifications of bingewatching television through Netflix. First Monday, 20(10). doi:10.5210/fm.v20i10.6138

Rand, D. G. (2012). The promise of Mechanical Turk: How online labor markets can help theorists run behavioral experiments. Journal of Theoretical Biology, 299, 172-179. doi:10.1016/j.jtbi.2011.03.004 
Riggle, E. D. B., Ellis, A. L., \& Crawford, A. M. (1996). The impact of "media contact" on attitudes towards gay men. Journal of Homosexuality, 31(3), 55-69.

Rubin, A. M., \& Perse, E. M. (1987). Audience activity and soap opera involvement: A uses and effects investigation. Human Communication Research, 14(2), 246-268. doi:10.1111/j.14682958.1987.tb00129.x

Rubin, A. M., Perse, E. M., \& Powell, R. A. (1985). Loneliness, parasocial interaction, and local television news viewing. Human Communication Research, 12(2), 155-180. doi:10.1111/j.14682958.1985.tb00071.x

Rubin, R. B., \& McHugh, M. P. (1987). Development of parasocial interaction relationships. Journal of Broadcasting and Electronic Media, 31(3), 279-292. doi:10.1111/j.1468-2958.1987.tb00129.x

Rubin, R. B., \& Rubin, A. M. (2001). Attribution in social and parasocial relationships. In V. Manusov \& J. H. Harvey (Eds.), Attribution, communication behavior, and close relationships (pp. 320-337). Cambridge, UK: Cambridge University Press.

Schiappa, E., Gregg, P. B., \& Hewes, D. E. (2005). The parasocial contact hypothesis. Communication Monographs, 72(1), 92-115. doi:10.1080/0363775052000342544

Schiappa, E., Gregg, P. B., \& Hewes, D. E. (2006). Can one TV show make a difference? Will \& Grace and the parasocial contact hypothesis. Journal of Homosexuality, 51(4), 15-37.

Schweidel, D. A., \& Moe, W. W. (2016). Binge watching and advertising. Journal of Marketing, 80 (5), 1-19. doi:10.1509/jm.15.0258

Slater, M. D., \& Rouner, D. (2002). Entertainment-education and elaboration likelihood: Understanding the processing of narrative persuasion. Communication Theory, 12(2), 173-191. doi:10.1111/j.1468-2885.2002.tb00265.x

Slater, M. D., Rouner, D., \& Long, M. (2006). Television dramas and support for controversial public policies: Effects and mechanisms. Journal of Communication, 56(2), 235-252. doi:10.1111/j.1460-2466.2006.00017.x

Smith, S. L., Choueiti, M., \& Pieper, K. (2016). Inclusion or invisibility? Comprehensive Annenberg report on diversity in entertainment. Los Angeles, CA: University of Southern California.

Tal-Or, N., \& Cohen, J. (2010). Understanding audience involvement: Conceptualizing and manipulating identification and transportation. Poetics, 38(4), 402-418. doi:10.1016/j.poetic.2010.05.004

Tian, Q., \& Hoffner, C. A. (2010). Parasocial interaction with liked, neutral, and disliked characters on a popular TV series. Mass Communication and Society, 13(3), 250-269. doi:10.1080/15205430903296051

Tretbar, A. (2014). Amazon orders second season for wildly popular original series ?Transparent'. Digital Trends. Retrieved from http://www.digitaltrends.com/home-theater/amazon-renewsoriginal-series-transparent-for-second-season/

Tukachinsky, R. H. (2010). Para-romantic love and para-friendships: Development and assessment of a multiple parasocial relationships scale. American Journal of Media Psychology, 3(1/2), 73-94.

Walton-Pattison, E., Dombrowski, S. U., \& Presseau, J. (2016). "Just one more episode": Frequency and theoretical correlates of television binge watching. Journal of Health Psychology. doi:10.1177/1359105316643379

Warren, S. M. (2016, August). Binge-watching rate as a predictor of viewer transportation mechanisms (Master's thesis). Syracuse University, Syracuse, NY. 